\title{
Abnormal Platelet Response to Thromboxane $\mathrm{A}_{2}$
}

\author{
Kenneth K. Wu, Guy C. Le Breton, Hsin-Hsiung Tai, and Yao-Chang Chen, \\ Department of Medicine, Rush Medical College, Rush-Presbyterian-St. Luke's \\ Medical Center, Department of Pharmacology, University of Illinois Medical \\ Center, Chicago, Illinois 60612; Department of Biochemistry, Texas College of \\ Osteopathic Medicine, Denton, Texas 76203
}

A в S T RACT To determine the pathogenetic mechanism of a hereditary primary platelet release disorder, arachidonic acid metabolism via the cyclooxygenase pathway was investigated. The propositus' platelets exhibited defective release reaction and secondwave aggregation when stimulated by sodium arachidonate or $\mathrm{U} 46619$, a thromboxane $\mathrm{A}_{2}\left(\mathrm{TXA}_{2}\right)$ agonist. The lack of platelet response to U46619 suggested that the defect was beyond the thromboxane synthetase level. Furthermore, thromboxane $\mathrm{B}_{2}\left(\mathrm{TXB}_{2}\right)$ formation in the propositus' platelets $\left(558.52 \mathrm{ng} / 10^{8}\right.$ platelets) was within the normal range $(574.29 \pm$ SD 27.39 $\mathrm{ng} / 10^{8}$ platelets) and $\mathrm{TXA}_{2}$ formation appeared to be adequate for aggregating normal platelets. The results were indicative of an abnormal platelet response to $\mathrm{TXA}_{2}$. Failure of the propositus' platelets to aggregate in response to $\mathrm{TXA}_{2}$ formed in normal platelet-rich plasma induced by arachidonate confirmed this notion. To gain further insight, platelet cyclic (c)AMP content was determined. Prostacyclin induced a significant elevation of the propositus' platelet cAMP level comparable to normal values. U46619 suppressed prostaglandin $\mathrm{I}_{2}$-induced cAMP elevation in normal subjects but had no such effect in the patient. We conclude that the primary release disorder observed in this kindred is due to an abnormal platelet response to $\mathrm{TXA}_{2}$ possibly because of $\mathrm{TXA}_{2} / \mathrm{PGH}_{2}$ receptor abnormalities.

\section{INTRODUCTION}

Thromboxane $\mathrm{A}_{2}\left(\mathrm{TXA}_{2}\right)^{1}$ plays an important role in mediating the platelet release reaction (1). When platelets are stimulated by aggregating agents, arachidonic

A preliminary report of this research was presented at The 72nd Annual Meeting of the American Society of Clinical Investigation, Washington, D. C., 10 May 1980, and published in abstract form. (1980. Clin. Res. 28: 498A.)

Received for publication 16 March 1981.

${ }^{1}$ Abbreviations used in this paper: $\mathrm{PGH}_{2}$, prostaglandin $\mathrm{H}_{2}$; PGI, prostacyclin; PRP, platelet-rich plasma; TXA $_{2}$, thromboxane $A_{2} ; \mathrm{TXB}_{2}$, thromboxane $\mathrm{B}_{2}$. acid is liberated from the membrane phospholipids and converted by cyclooxygenase to the cyclic endoperoxides (prostaglandin $\mathrm{G}_{2}$ and $\mathrm{H}_{2}$ ) that are further converted to $\mathrm{TXA}_{2}$ by thromboxane synthetase $(2-5)$. Although the mechanism of $\mathrm{TXA}_{2}$ action in platelet aggregation is unknown, it appears to be involved in the regulation of intracellular cyclic (c)AMP levels. In this regard, $\mathrm{TXA}_{2}$ does not lower the basal level of cAMP in platelets, yet it does inhibit $\mathrm{PGI}_{2}$-stimulated cAMP accumulation (6). The physiological significance of $\mathrm{TXA}_{2}$ may be demonstrated in a heterogenous group of human bleeding disorders characterized by a cyclooxygenase deficiency and a primary defect in the platelet release reaction (7-9). We have previously reported a kindred with a similar release disorder (10) in that platelet aggregation in response to arachidonic acid was subnormal. Further investigations of this patient demonstrated that the release defect was not due to altered production of $\mathrm{TXA}_{2}$ but rather due to a defect in platelet responsiveness to $\mathrm{TXA}_{2}$.

\section{METHODS}

Patient. Clinical and functional abnormalities of this kindred were described (10). Only the propositus was available for this study. In brief, she was a 26 -yr-old woman with a life-long history of mild bleeding. She exhibited a prolonged bleeding time and reduced platelet release reaction and second-wave aggregation in response to ADP, collagen, and epinephrine. Shape change and primary aggregation in response to ADP were normal. Furthermore, her platelets aggregated normally to thrombin, ionophore A23187, and ristocetin.

Materials. Sodium arachidonate was prepared by dissolving arachidonic acid (Sigma Chemical Co., St. Louis, Mo.) in $0.1 \mathrm{M}$ sodium carbonate, $\mathrm{pH}$ 10.0. U46619 [(15S)hydroxy-1 $1 \alpha, 9 \alpha$-(epoxymethanol)-prosta-5Z, and $13 \mathrm{E}$ dienoic acid] and prostacyclin $\left(\mathrm{PGI}_{2}\right)$, kindly supplied by $\mathrm{U}_{\text {pjohn }} \mathrm{Co}$., Kalamazoo, Mich., were dissolved in ethanol and in $0.05 \mathrm{M}$ Tris buffer, $\mathrm{pH} 9.40$, respectively.

Platelet thromboxane $B_{2}\left(T X B_{2}\right)$ formation. Blood was drawn from an antecubital vein into polypropylene tubes containing one-tenth vol of $3.8 \%$ sodium citrate, mixed and centrifuged at $200 \mathrm{~g}$ for $10 \mathrm{~min}$. Platelet-rich plasma (PRP) was collected and the remaining sample was further centrifuged at $1,000 \mathrm{~g}$ for $20 \mathrm{~min}$ to prepare platelet-poor plasma. 
Platelet concentration of the PRP was adjusted to $3 \times 10^{8} / \mathrm{ml}$ with autologous platelet-poor plasma. PRP $(0.5 \mathrm{ml})$ was preincubated in a cuvette of the Payton dual channel aggregometer (Payton Associates, Buffalo, N. Y.) for $1 \mathrm{~min}$ and $1 \mathrm{mM}$ sodium arachidonate was added. The mixture was stirred at $37^{\circ} \mathrm{C}$ for $3 \mathrm{~min}$ and then acidified to $\mathrm{pH} 3.0$ with $1 \mathrm{~N} \mathrm{HCl}$. $\mathrm{TXB}_{2}$ was extracted with $3 \mathrm{ml}$ ethylacetate twice and dried under nitrogen gas at $50^{\circ} \mathrm{C}$. The dried material was reconstituted and applied to a silicic acid column $(0.5 \mathrm{~g} / \mathrm{ml})$ and the $\mathrm{TXB}_{2}$ fraction was collected and dried under nitrogen (11). The dried extract was reconstituted in $1 \mathrm{ml}$ of radioimmunoassay buffer and assayed according to a previously described radioimmunoassay method (12). $\mathrm{TXB}_{2}$ recovery was determined by adding a known quantity of $\left[{ }^{3} \mathrm{H}\right] \mathrm{TXB}_{2}$ (New England $\mathrm{Nu}$ clear, Boston, Mass.) in a control sample and the recovery at the end of extraction was calculated. The average yield in our laboratory was $80 \%$. The $\mathrm{TXB}_{2}$ radioimmunoassay displayed minimal cross-reactivity with other prostaglandin-type compounds and proved to be sensitive to $5 \mathrm{pg}$ per assay tube (12).

Platelet aggregation study. Platelet aggregation was performed as previously described (13) using a Payton dual channel aggregometer. To demonstrate $\mathrm{TXA}_{2}$ formation, transfer experiments were carried out in the aggregometer according to the procedure described by Hamberg et al. (4). In brief, $1 \mathrm{mM}$ arachidonate was added to $0.5 \mathrm{ml}$ of PRP in a Payton aggregometer. After stirring at $37^{\circ} \mathrm{C}$ for $30 \mathrm{~s}, 0.1 \mathrm{ml}$ was rapidly transferred to the second tube that contained 0.45 $\mathrm{ml}$ normal PRP pretreated with aspirin, and the aggregation was determined.

Platelet cAMP study. The functional responsiveness of platelets to $\mathrm{TXA}_{2}$ was investigated by examining their response to $\mathrm{U} 46619$, a relatively stable $\mathrm{TXA}_{2}$ agonist. $\mathrm{PGI}_{2}$ stimulates adenylate cyclase, leading to an increase in basal cAMP levels (14). Since TXA ${ }_{2}$ or U46619 inhibits PGI $_{2}$-stimulated cAMP accumulation in normal platelets, we investigated the ability of U46619 to inhibit $\mathrm{PGI}_{2}$-stimulated cAMP in the propositus' platelets. PRP was divided into four 4-ml aliquots. In aliquot 1, PRP was incubated with U46619 (final concentration $3 \mu \mathrm{M}$ ) for $90 \mathrm{~s}$ at room temperature. $3 \mathrm{nM}$ freshly prepared $\mathrm{PGI}_{2}$ was added and incubated for an additional $90 \mathrm{~s}$. In aliquot 2, PRP was incubated with ethanol for $90 \mathrm{~s}$ followed by $\mathrm{PGI}_{2}$ for an additional $90 \mathrm{~s}$. In aliquot 3 , PRP was incubated with U46619 for $90 \mathrm{~s}$ followed by Tris buffer for an additional $90 \mathrm{~s}$, and in aliquot 4, PRP was incubated with ethanol for $90 \mathrm{~s}$ followed by Tris buffer for an additional $90 \mathrm{~s}$. The mixtures were quickly frozen in liquid nitrogen and stored at $-70^{\circ} \mathrm{C}$ until assay. The samples were kept at $-70^{\circ} \mathrm{C}<48 \mathrm{~h}$. The cAMP content in these samples was determined in quadruplicate by the protein binding method of Gilman (15).

\section{RESULTS}

Platelet aggregation in response to sodium arachidonate was completely absent in the propositus (Fig. 1A, B). These results were suggestive of either cyclooxygenase or thromboxane synthetase deficiency. However, platelet $\mathrm{TXA}_{2}$ formation in the patient (558.52 $\mathrm{ng} \mathrm{TXB}_{2} / 10^{8}$ platelets) was within the normal range $\left(n=5,574.29 \pm \mathrm{SD} 27.39 \mathrm{ng} \mathrm{TXB}_{2} / 10^{8}\right.$ platelets). Furthermore, U46619, a $\mathrm{TXA}_{2}$ agonist that normally induces maximal aggregation at $4 \mu \mathrm{M}$, had no apparent effect on the patient's platelets (Fig. 1C, D). These findings led us to postulate that the release de- fect was probably due to an abnormal platelet response to $\mathrm{TXA}_{2}$. To test this hypothesis, transfer experiments were performed. No aggregation was observed when arachidonate-treated normal PRP was transferred to the patient's platelets. By contrast, transfer of arachidonate-treated patient PRP to normal PRP resulted in platelet aggregation (Fig. 1E, F). These findings indicate that the patient's platelets were in fact capable of synthesizing $\mathrm{TXA}_{2}$ in response to arachidonate, but that they were unresponsive to the $\mathrm{TXA}_{2}$ that was produced.

To further substantiate the platelet unresponsiveness to $\mathrm{TXA}_{2}$, the effects of $\mathrm{PGI}_{2}$ and $\mathrm{U} 46619$ on platelet cAMP levels were investigated. While $\mathrm{PGI}_{2}$ induced a significant elevation of platelet CAMP in the patient, U46619 failed to suppress this increase (Fig. 2). In contrast, U46619 was capable of suppressing cAMP elevation induced by $\mathrm{PGI}_{2}$ in five normal controls. Although the $\mathrm{PGI}_{2}$-induced cAMP elevation in the patient appears lower than control, it is within two standard deviations of the normal value.

\section{DISCUSSION}

It is generally believed that the primary release disorder of platelets is related to abnormality of one or more of the enzymes involved in arachidonic acid metabolism. However, the disorder observed in this patient appears to be due to a different mechanism since platelet $\mathrm{TXA}_{2}$ formation in response to arachidonic acid is completely normal. We believe therefore, that the disorder is due to a defect in platelet responsiveness to $\mathrm{TXA}_{2}$. This notion is supported by three lines of evidence. Firstly, the transfer of $\mathrm{TXA}_{2}$ formed in normal PRP failed to elicit platelet aggregation in this patient. Secondly, platelet aggregation in response to U46619, which presumably acts directly on $\mathrm{TXA}_{2} /$ $\mathrm{PGH}_{2}$ receptors (16), was absent in this patient. Thirdly, U46619 failed to suppress the cAMP elevation induced by $\mathrm{PGI}_{2}$ in this patient, while it was capable of antagonizing the $\mathrm{PGI}_{2}$ effect in normal platelets.

The abnormal platelet responsiveness may be due to a number of mechanisms, notably membrane abnormalities and/or a generalized disturbance in intracellular $\mathrm{Ca}^{2+}$ mobilization. The latter seems unlikely, however, because the patient's platelets respond normally to ionophore A23187 and thrombin, both of which are thought to act through the redistribution of intraplatelet $\mathrm{Ca}^{2+}$. Moreover, the platelets exhibit normal shape change and primary aggregation when stimulated by ADP. Based on these considerations it would appear that the basic defect is most likely related to membrane abnormalities. Since, however, the patient's platelets respond normally to a myriad of aggregating agents with distinctive receptor sites on the platelet membrane, we do not think that there is a 


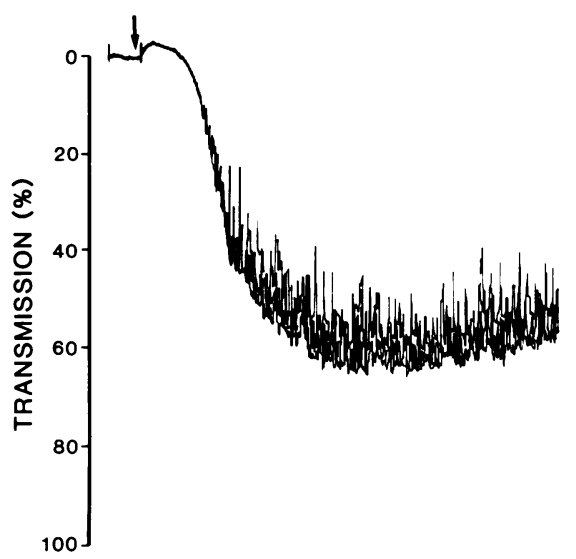

A
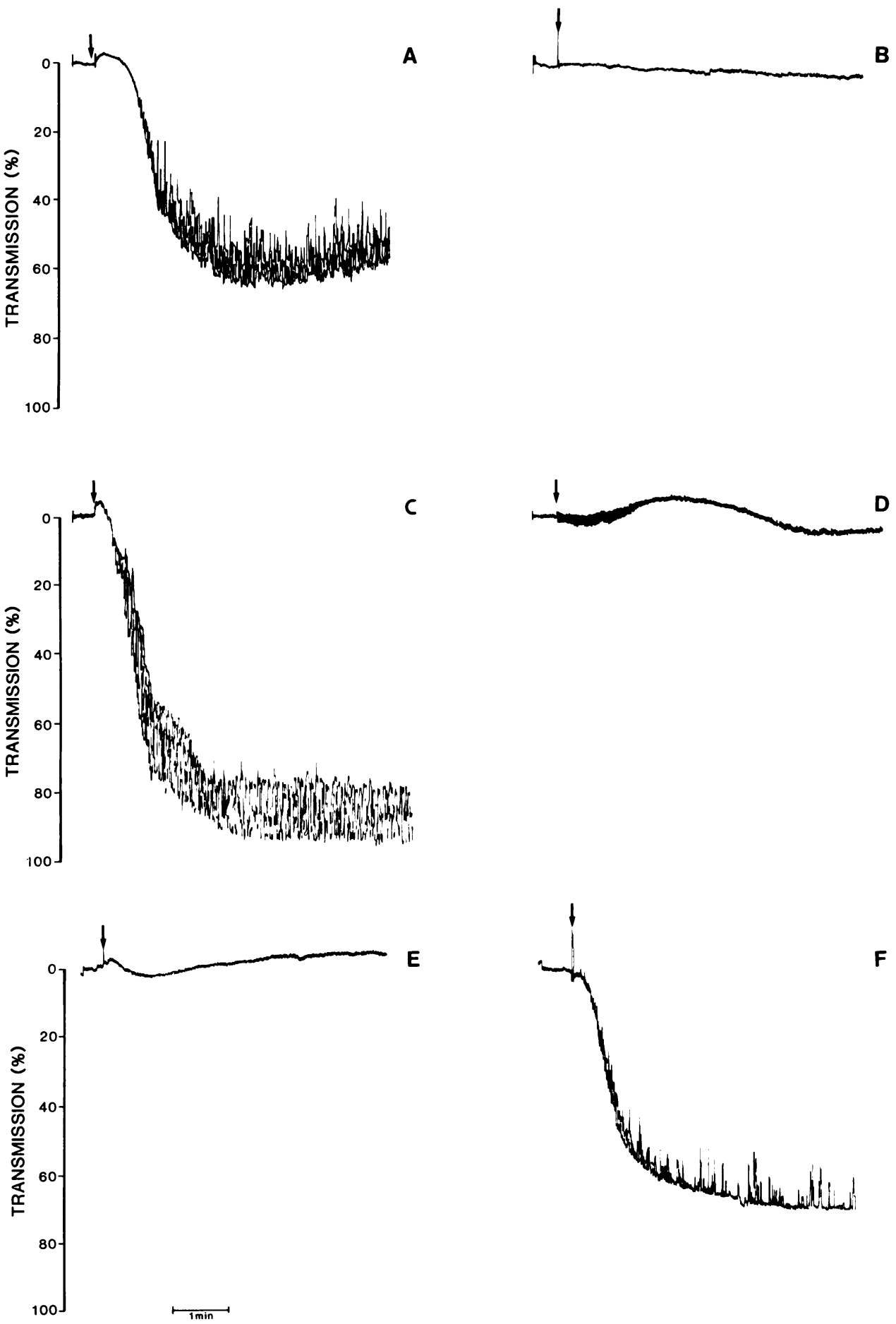

FIGURE 1 Representative platelet aggregation tracings: (A) Platelet aggregation in response to sodium arachidonate $(1 \mathrm{mM})$ in a normal subject; (B) Arachidonate-induced aggregation in the propositus; (C) Aggregation in response to U46619 (4 $\mu \mathrm{M})$ in normal subjects; (D) U46619induced aggregation in the propositus. $E$ and $F$ are aggregation tracings from the transfer experiments. Aggregation did not occur when $0.1 \mathrm{ml}$ of normal PRP, preincubated with sodium arachidonate for $30 \mathrm{~s}$ was rapidly transferred to patient PRP (E). In contrast, transfer of patient PRP pretreated with sodium arachidonate resulted in aggregation in normal platelets $(\mathbf{F})$. Arrows refer to addition of aggregating agents. 


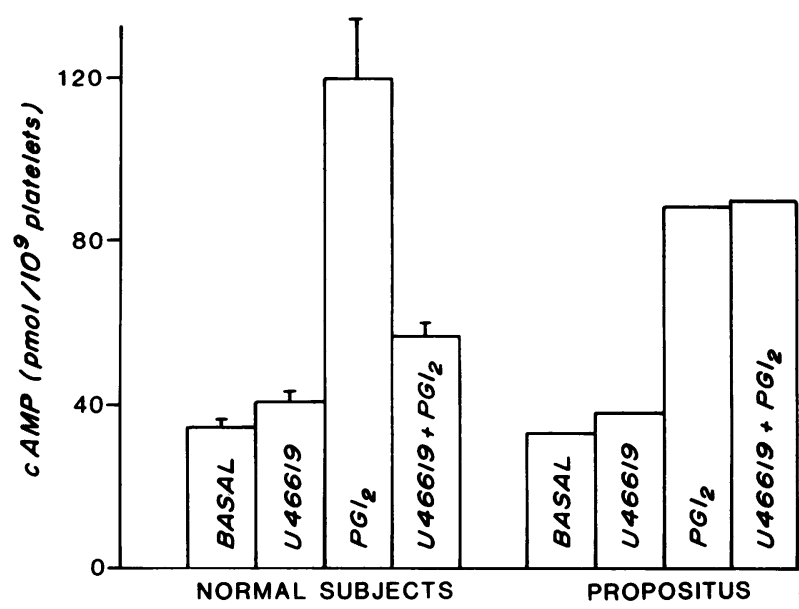

Figure 2 Changes in platelet cAMP content in response to $\mathrm{PGI}_{2}$ and U46619. cAMP was determined in quadruplicate. Five normal subjects were included and each bar represents mean \pm SD. Basal and U46619-induced platelet cAMP levels of the propositus were comparable to those of normal subjects. The $\mathrm{PGI}_{2}$-induced cAMP level in the patient was slightly below 1 SD but within 2 SD of the normal value. Pretreatment of patient's platelets with U46619 failed to suppress $\mathrm{PGI}_{2}$-induced cAMP elevation. $n=5$.

global membrane defect. In view of the fact that the patient's platelets have a subnormal response to $\mathrm{TXA}_{2}$ and its agonist in terms of cAMP suppression and platelet aggregation, we suggest that the defect is due to a specific $\mathrm{TXA}_{2} / \mathrm{PGH}_{2}$ receptor abnormality.

\section{ACKNOWLEDGMENTS}

We are indebted to Dr. Wilbanks for referring the patient for study, Dr. Elizabeth R. Hall for suggestions concerning the manuscript, and Dr. Robert Gorman for suggestions concerning cAMP study. We are grateful to Dr. John Pike and Dr. Udo Axen at the Upjohn Co. for kindly supplying various prostaglandin compounds. The excellent technical assistance of Debbie Matayoshi, Lynn Doglio, and Michael McNeal, and the excellent secretarial help of Ms. Rosa Ocasio are highly appreciated.

This work was supported in part by a grant from the National Institutes of Health GM 25247, and the American Heart Association, 77-1039, 78-865, and 79-895.

\section{REFERENCES}

1. Marcus, A. J. 1978. The role of lipids in platelet function: with particular reference to the arachidonic acid pathway. J. Lipid Res. 19: 793-826.
2. Smith, J. B., C. Ingerman, J. J. Kocsis, and M. G. Silver. 1974. Function of an intermediate prostaglandin biosynthesis and its association with the platelet release reaction. J. Clin. Invest. 53: 1468-1472.

3. Hamberg, M., and B. Samuelsson. 1974. Prostaglandin endoperoxides. Novel transformations of arachidonic acid in human platelets. Proc. Natl. Acad. Sci. U. S. A. 71: 3400-3404.

4. Hamberg, M., J. Svensson, and B. Samuelsson. 1975. Thromboxanes: a new group of biologically active compounds derived from prostaglandin endoperoxides. Proc. Natl. Acad. Sci. U. S. A. 72: 2994-2998.

5. Needleman, P., S. Moncada, S. Bunting, J. R. Vane, M. Hamberg, and B. Samuelsson. 1976. Identification of an enzyme in platelet microsomes which generate thromboxane $\mathrm{A}_{2}$ from prostaglandin endoperoxides. Nature (Lond.). 26: 558-560.

6. Gorman, R. R. 1979. Modulation of human platelet function by prostacyclin and thromboxane $\mathrm{A}_{2}$. Fed. Proc. 38: $83-88$.

7. Malmsten, C., M. Hamberg, J. Svensson, and B. Samuelsson. 1975. Physiological role of an endoperoxide in human platelets: haemostatic defect due to platelet cyclooxygenase deficiency. Proc. Natl. Acad. Sci. U. S. A. 72: $1446-1450$

8. LaGarde, M., P. A. Byron, B. B. Vargaftig, and M. Dechavenne. 1978. Impairment of platelet thromboxane $A_{2}$ generation and of the platelet release reaction in two patients with congenital deficiency of platelet cyclooxygenase. Br. J. Haematol. 38: 251-266.

9. Pareti, F. I., P. M. Mannucci, and A. D'Angelo. 1980. Congenital deficiency of thromboxane and prostacyclin. Lancet. I: 898-900.

10. Wu, K. K., I. M. Minkoff, E. C. Rossi, and Y. C. Chen 1981. Hereditary bleeding disorder due to a primary defect in platelet release reaction. $\mathrm{Br}$. J. Haematol. 47: 241-249.

11. Unger, W. G., I. F. Stamford and A. Bennet. 1971. Extraction of prostaglandins from human blood. Nature (Lond.). 233: 336-337.

12. Tai, H. H., and B. Yuan. 1978. Development of radioimmunoassay for thromboxane $\mathrm{B}_{2}$. Anal. Biochem. 87: 343-349.

13. Wu, K. K. 1978. Platelet hyperaggregability and thrombosis in patients with thrombocythemia. Ann. Intern. Med. 88: 7-11.

14. Gorman, R. R., S. Bunting, and O. U. Miller. 1977. Modulation of human platelet adenylate cyclase by prostacyclin (PGX). Prostaglandins. 13: 377-388.

15. Gilman, A. G. 1970. A protein binding assay for adenosine 3'; 5-cyclic monophosphate.Proc. Natl. Acad. Sci. U. S. A. 67: 305-312.

16. Le Breton, G. C., D. L. Venton, S. E. Enke, and P. V. Halushka. 1979. 13-Azaprostanoic acid: a specific antagonist of the human blood platelet thromboxane/endoperoxide receptor. Proc. Natl. Acad. Sci. U. S. A. 76: 4097-4101. 